\title{
The effect of social media interactions on customer relationship management
}

\author{
Olaf Maecker ${ }^{1} \cdot$ Christian Barrot $^{2} \cdot$ Jan U. Becker ${ }^{2}$
}

Received: 14 July 2015/ Accepted: 22 January 2016/Published online: 10 February 2016

(C) The Author(s) 2016. This article is published with open access at Springerlink.com

\begin{abstract}
In recent years, social media have become a popular channel through which customers and companies can interact. However, companies struggle to assess whether their investments in establishing and maintaining brand pages in social media actually meet their high expectations with respect to developing and retaining customers. Based on three empirical studies, the authors explore the role of interactions through corporate social media channels, such as Facebook brand pages, in customer relationship management. The results indicate that social media interactions indeed ease the upselling efforts and reduce the risk of churn. These positive effects offset the observed increases with regard to the number of service requests and the higher overall service cost. Thus, we ultimately find customers who interact with the brand on social media to be more profitable.
\end{abstract}

Keywords Social media - Brand pages - Customer relationship management . Customer lifecycle

Jan U. Becker

jan.becker@the-klu.org

Olaf Maecker

olaf@olafmaecker.com

Christian Barrot

christian.barrot@the-klu.org

1 Institute for Marketing, University of Hamburg, Hamburg, Germany

2 Kühne Logistics University, Großer Grasbrook 17, 20457 Hamburg, Germany 


\section{Introduction}

Hoping that direct interaction with customers may raise customer relationships to the next level, more than 100,000 companies to date have established brand pages on social media platforms such as Facebook. Social media are Internet-based applications that allow customers and companies to interact by creating, sharing, or exchanging information (Kaplan and Haenlein 2010). Considering that each company's social media efforts require substantial investments (e.g., establishing and maintaining brand pages), a fundamental question remains: Are social media efforts worthwhile, and do they translate into better and altogether more profitable customers?

Defining social media interactions as brand-related communication between companies and customers and between customers via company-managed social media channels such as brand pages, this study is based on previous research. Recent research has advocated the value of social media interactions for companies that propose conceptual frameworks to manage brands (Gensler et al. 2013) and customers (Malthouse et al. 2013), develop metrics (Peters et al. 2013), and assess the marketing potential in the social media context (Yadav et al. 2013). However, there is a need for a deeper understanding of the implications of social media (Hennig-Thurau et al. 2013), specifically one based on empirical evidence.

In three explorative studies involving data from a mobile phone provider on customer-level demographics, contract history, customer service requests, and social media usage, we investigate the link among social media interactions with the firm and customers' upselling behavior, churn, and service contacts. The results indicate that social media interactions indeed ease the upselling efforts and reduce the risk of churn. These positive effects offset the observed increases with regard to the number of service requests and the higher overall service cost. Thus, we ultimately find customers who interact with the brand on social media to be more profitable.

\section{Conceptual background}

In recent years, social media have become ubiquitous for users and companies. Approximately 1.2 billion people use Facebook worldwide to follow brands (53\% at least once per month), learn more about brands $(65 \%)$ or hear of others' experiences with brands (70\%; The Nielsen Company 2012). Consequently, companies following a multi-channel customer management approach (Neslin et al. 2006; Neslin and Shankar 2009) invest heavily in social media by establishing brand fan pages on which companies convey brand-related content (i.e., brand posts) that users can like, comment on, or share, and the company can react with comments of their own (De Vries et al. 2012; Labrecque 2014). These open, social media-enabled interactions between a company and its customers help create a community that revolves around the brand and fosters the brand relationship (McAlexander et al. 2002; Muniz and O'Guinn 2001). In this study, we analyze the brand-related 
interactions between customers and a mobile phone provider. The examples provided in the paper hence refer to this context.

Although there is a large body of research on the various positive implications of brand communities (for an overview, refer to Gruner et al. 2014), challenges with respect to the management of customer relationships and its implications on the development and retention of customers, as well as their profitability, remain (Malthouse et al. 2013). Without knowing how social media influence customer relationships, companies struggle to assess the return on their investments. This study addresses this research gap and provides an analysis of the effect of social media interactions with the firm on upselling behavior, customer churn, and service contacts as well as its implications on the profitability of social media activities.

The question regarding how social media interactions influence the post-purchase decisions of customers is crucial for companies. Once customers have purchased a product or service, social media enable customers to share their consumption experience with their social network. For instance, consumers can like, rate, review, or comment on the brand (Hennig-Thurau et al. 2004, 2015). Additionally, customers can actively refer the product or service to others by recommending or sharing information (Yadav et al. 2013). In both cases, the post-purchase involvement helps other users validate their opinions regarding specific products or services (Schau et al. 2009). In this regard, social media interactions resemble word-of-mouth (WOM) in which prospective customers receive product information from trusted sources in their social network (Dichter 1966). However, social media also provides users with a platform to voice negative customer experiences (Hennig-Thurau et al. 2004). For instance, $50 \%$ of social media users express complaints regarding brands at least once per month (The Nielsen Company 2012), which changes customer complaints from a private to a public phenomenon (Ward and Ostrom 2006). Using social media platforms, consumers can cheaply voice their dissatisfaction, easily reach a large audience and, consequently, effectively harm the brand (e.g., Chevalier and Mayzlin 2006; Elsner et al. 2010).

Given companies' intention to expand customer relationships and to increase customer revenues, WOM affects not only the sales of other customers (Chevalier and Mayzlin 2006; Hinz et al. 2011) but also the sales of the senders, repeat purchases, or additional purchases through up- or cross-selling (Kumar et al. 2010; Armelini et al. 2015). Up- or cross-selling in the mobile phone context could involve extended talk or data plans, hardware, or auxiliary services (e.g., Company: "Upgrade your data plan and get 1 GB data free!"). In this case, social media interactions serve as a source of information from which customers learn about products and services and form their attitude regarding them. This information sharing occurs not only by following company-initiated brand posts but also by actively interacting with the brand (e.g., commenting, liking, or inquiring on information such as User: "I really like the iPhone. When do you start selling it?"). Through such frequent social media interactions, attitudes towards the brand become more accessible for prospective customers. Consequently, the increase in the attitude accessibility facilitates customers' subsequent purchasing behavior (Downing et al. 1992; Morwitz et al. 1993). Although frequent brand-related interactions via social media and the subsequent increased involvement of 
customers with positive experiences would reflect higher up- and cross-selling and further developed customer relationships, we would expect the opposite effect for those who voice their negative experiences.

The same applies to the effect of social media interactions on customer churn. The research proposes that customer interactions create engagement value for the company, which has a positive effect on customer retention and, ultimately, the customer value (e.g., Kumar et al. 2010; Van Doorn et al. 2010; Verhoef et al. 2010). In particular, customer engagement, such as participation in positive WOM, increases the commitment and social identification with the brand as well as the brand community and leads to higher customer retention (Brodie et al. 2013). Most likely, only social media interactions that are driven by positive customer experiences would exert similar customer reactions and affect customer retention positively. This effect would certainly not hold for negative customer experiences, which lead to uncertainty regarding the overall effect of social media interactions for companies.

Apparently, the uncertainty regarding the effects of social media interactions on customers' upselling behavior and churn depends highly on the previous service experience of customers. Hence, reacting appropriately to complaints has become a major challenge (Bolton and Saxena-Iyer 2009; Hennig-Thurau et al. 2010) and an opportunity for both companies and their social media activities. The research indicates that companies that take appropriate remedial actions in a timely manner show that they are sensitive to customer concerns (Van Laer and De Ruyter 2010; Van Noort and Willemsen 2012). If companies respond via social media platforms, the resulting favorable brand evaluations are visible to other customers and have an outreach effect that is nearly equivalent to that of the complaints (e.g., User: "Help. I have had no coverage for $3 \mathrm{~h}$ now. Is there a problem with the network?", Company: "Hello User, have you tried to restart your mobile? If you send us your address, we can check if there is a local disturbance."). Therefore, adequate customer service via social media, which is called social care, is not only a strategic necessity for customer relationship management (47\% of social media users engage in social care; The Nielsen Company 2012) but also a viable means to reduce customer service costs. Social care can directly manage dissatisfied customers and offer solutions to the problems associated with the complaints (Bernoff and Schadler 2010). In this case, social care replaces costly offline customer service contacts (e.g., via telephone; Aksin et al. 2007). Furthermore, social care promises to be much more efficient than previous bilateral customer service encounters. Companies also benefit from the publicity that successful social media interactions between customers and companies regarding complaints draw. First, customers may be prevented from encountering the same problem and, hence, from experiencing dissatisfaction. Second, customers who encounter the same problem learn about the solution and thus will not need to contact the company to seek a remedy. In this regard, social media interactions in the form of social care could decrease the number of customer service requests and the subsequent costs by replacing and preventing offline customer service contacts.

To determine any meaningful insights into the actual profitability of social media activities, the required investment in such channel needs to be specified as well. 
Social media interactions with (potential) customers do not come for free but require investments in external consulting (e.g., to determine the social media strategy), internal staff (e.g., community managers) as well as additional spending for building the specific social media site or app (see, for example Digitalbuzz 2011). Such cost are-compared to, for example, advertising — not very transparent though. And despite academic research frequently postulates that they are "relatively low" compared to other channels (see, e.g., Kaplan and Haenlein 2010), industry sources estimate six-digit budgets even for simple campaigns (see Digitalbuzz 2011). A further complication is that the traditional process of spending might not be applicable for social media (see Weinberg and Pehlivan 2011). Hoffman and Fodor (2010) even argue that traditional ROI measures cannot be applied to social media. Rather than focusing on the firm's investment, marketing managers should look at the customer's investment when interacting in such channels.

Considering companies' uncertainty regarding the revenue and cost implications of social media interactions, we report on three empirical analyses that investigate the effect social media interactions have on customers' upselling behavior, churn, and service contacts.

\section{Empirical analyses}

\subsection{Data and measures}

The data used in this study were obtained from a mobile phone service provider in a major European country and capture all customer-related activities of this firm from its market entry in April 2012 until July 2014 (856 days in total). In particular, the dataset encompasses information on 334,111 customers and includes their demographic information (such as gender, age, or household purchasing power) and contract history (such as the dates of the contract start, product upgrade, or termination) as well as data on all individual interactions with the company's customer service (via telephone or email; in total, 585,754 interactions). The company offers telecommunication services in the form of a subscription-based talk, text, and data plan. In addition to the flat-rate service for calls, customers can subscribe to optional upgrades to flat-rate text or data plans.

Most importantly, the firm operates a dedicated Facebook brand page as an integral part of its social media marketing activity. The company installed a professional community management system with a focus on content and social service from the beginning. The main objective is the proactive management of activities on the brand page and general "storytelling". The company generates specific content periodically to fuel interaction among users regarding major issues (e.g., hardware tests, surveys, special fan offers). Additionally, the social service is the reactive management of consumer activities. Consumers (customers and noncustomers) begin discussions with messages, requests, and complaints on the brand fan page and interact with other consumers. The community management enters the 


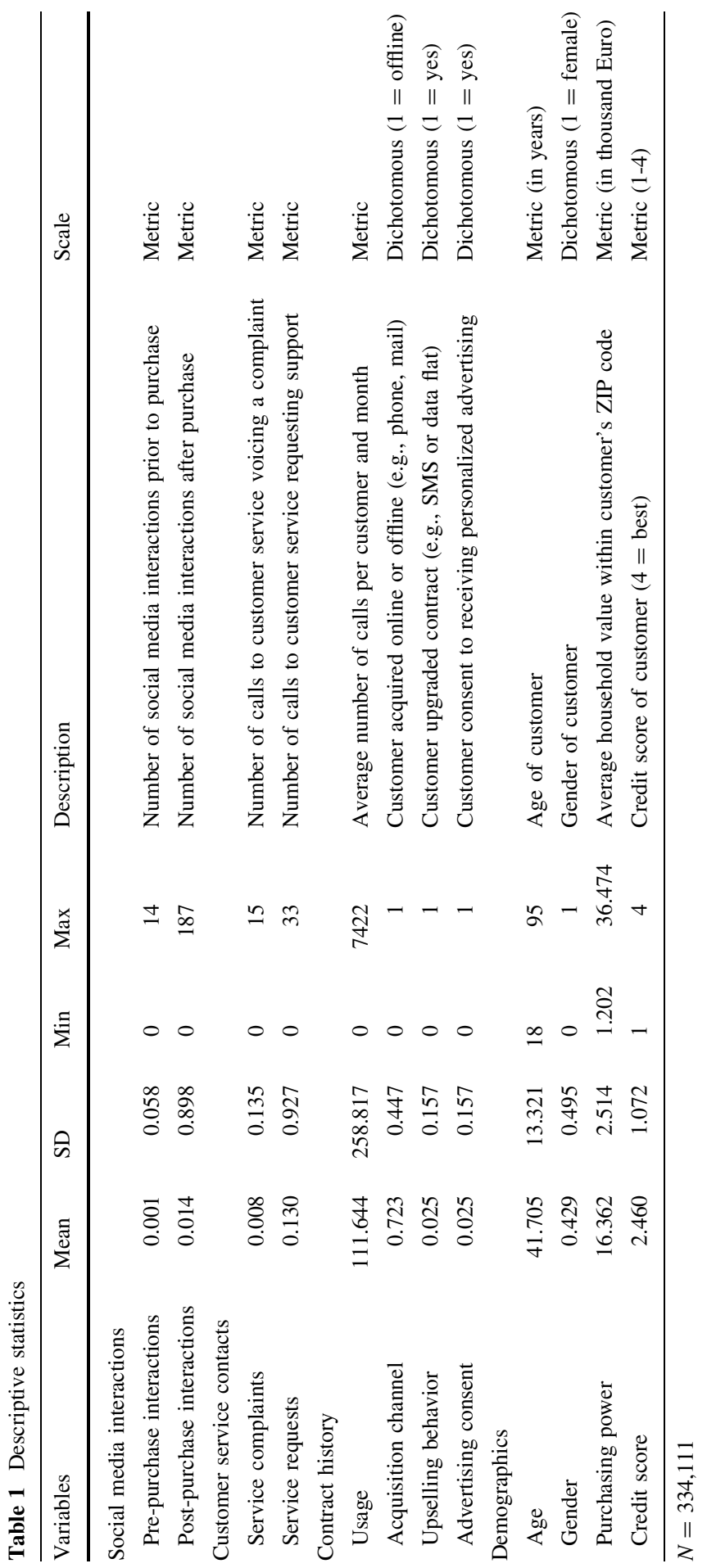


discussion to resolve problems in the public space. ${ }^{1}$ Hence, we have access to all 102,995 interactions with customers and non-customers on this site, specifically including all user-generated and company-generated content. Table 1 contains detailed information on the sample and the measures used for the individual analyses in the following studies. All individual-level data were encrypted, and the financial data were rescaled to comply with the company's privacy policies and financial disclosure regulations.

\subsection{Overview of analyses}

In the following, we present three empirical studies that investigate the proposed effects of social media interactions. Given that we do not have a controlled experimental setting, it is necessary to control for endogeneity and selection biases that may occur if customers with social media interactions differ from those without. Thus, we use the propensity score matching approach to reduce the selfselection effects in all three studies (Caliendo et al. 2012; Rosenbaum and Rubin 1983). Following Garnefeld et al. (2013), we first estimate the propensity score with the help of a binary logistic regression in which the dependent variable equals one for customers with social media interactions and zero otherwise. Because the estimation results for the full sample indicate a good fit to the data (refer to Appendix 1), we include all variables in our calculation of the propensity scores (Rubin and Thomas 2000) and use the nearest-neighbor matching procedure to match social media customers with similar non-social media customers. As shown in Appendix 2, the matching procedure helps significantly reduce the selection bias in the full sample because the treatment and control groups are distinct before the matching procedure and exhibit similar characteristics thereafter (based on the percentage reduction in bias; refer to Rosenbaum and Rubin 1985). Because the analyses consider different dependent variables (i.e., upselling behavior, contract terminations, and service contacts), three different propensity score matchings are needed (Table 2).

Our research is organized into three studies: first, we use a parametric Weibull hazard model to investigate how social media interactions affect the likelihood and timing of the upselling behavior. Specifically, we observe whether and, if they do, when customers chose to upgrade to a flat-rate SMS or data plan. We choose a hazard model approach because the observed customers vary significantly in their tenure; the key influence factors require a time-varying approach, and a large number of observations are right censored. Second, to analyze the effect of social media interactions on customer retention, we use a probit model with sample selection (heckprobit). The probit component of this modeling approach indicates the influence of social media interactions (and additional covariates) on customer retention for those customers who chose to interact via social media, whereas the sample selection component controls for endogeneity issues that originate in the self-selection of Facebook as a communication channel through a Heckman correction (Heckman 1979). Additionally, we compute the Kaplan-Meier estimates

\footnotetext{
1 According to the partner company, nearly $100 \%$ of all consumer-initiated activities are answered.
} 
Table 2 Overview of studies

\begin{tabular}{|c|c|c|c|}
\hline & Study 1 & Study 2 & Study 3 \\
\hline $\begin{array}{l}\text { Research } \\
\text { questions }\end{array}$ & $\begin{array}{l}\text { What is the effect of social } \\
\text { media interactions on the } \\
\text { likelihood and timing of } \\
\text { upselling behavior? }\end{array}$ & $\begin{array}{l}\text { a. What is the effect of social } \\
\text { media interactions on the } \\
\text { likelihood of customer } \\
\text { retention? } \\
\text { b. What is the effect of } \\
\text { social media interactions } \\
\text { on customer lifetime? }\end{array}$ & $\begin{array}{l}\text { What is the effect of } \\
\text { social media } \\
\text { interactions on } \\
\text { service contacts? }\end{array}$ \\
\hline $\begin{array}{l}\text { Dependent } \\
\text { variables }\end{array}$ & Upselling behavior & $\begin{array}{l}\text { a. Customer churn } \\
\text { b. Retention probability }\end{array}$ & $\begin{array}{l}\text { Service requests } \\
\text { Service complaints }\end{array}$ \\
\hline Method & Hazard model & $\begin{array}{l}\text { a. Probit model } \\
\text { b. Kaplan-Meier estimates }\end{array}$ & $\begin{array}{l}\text { Seemingly unrelated } \\
\text { regression }\end{array}$ \\
\hline $\begin{array}{l}\text { Correction of } \\
\text { sample } \\
\text { selection } \\
\text { bias }\end{array}$ & Propensity score matching & $\begin{array}{l}\text { a. Heckman correction } \\
\text { b. Propensity score matching }\end{array}$ & $\begin{array}{l}\text { Propensity score } \\
\text { matching }\end{array}$ \\
\hline $\begin{array}{l}\text { Sample size } \\
\quad \text { (unmatched) }\end{array}$ & 334,111 & a./b. 334,111 & 334,111 \\
\hline $\begin{array}{l}\text { Sample size } \\
\text { (matched) }\end{array}$ & 4154 & b. 8330 & 2916 \\
\hline
\end{tabular}

for contract terminations and analyze the customer survival over time (based on a matched sample). Thus, we are able to compare the churn behavior between the groups both stationary (at the end of our observation period) and over time (throughout the full observation period) to identify specific patterns when the churn risk of a customer changes during the contract tenure. Third, we use a seemingly unrelated regression approach to capture how the number of service contacts, i.e., service requests and complaints, are affected by social media interactions.

\subsection{Social media interactions and upselling behavior (Study 1)}

\subsubsection{Sample and measurement}

In Study 1, we use the data of all 334,111 customers who signed up for a contract in the first 856 days after launch to analyze the effect of social media interactions on the upselling behavior of customers. Specifically, we consider customers' decision to upgrade their product (for example, by adding a SMS flat rate or a data flat rate) to be the upselling behavior. The upselling behavior is a dichotomous (dependent) variable that solely considers the first service upgrade initiated by a customer. Based on the information of all social media activities of the customers on the company's brand page, we use the two variables, pre-purchase interactions (which count all interactions on the brand page before becoming a customer) and post-purchase interactions (which include all interactions on the brand page after becoming a 
customer), as focal independent variables. This appears to be appropriate because previous research has shown that the post-acquisition social influence helps customers re-affirm or validate their initial choice (e.g., Donnelly and Ivancevich 1970; Mudambi and Schuff 2010).

As covariates, we include information on customers' interactions with the customer service unit that provide insights on an alternative channel of customer interaction. Here, the number of service requests indicates how often customers contacted the company's customer service regarding general service issues such as invoice inquiries or customer detail changes. The variable, service complaints, quantifies the number of complaints that were received by the customer service unit. Both the social influence variable (pre-purchase and post-purchase interactions on the brand page) and the interaction variables with the customer service unit (service requests and complaints) are time-varying. The values for both variables are accumulated until the date of the first upselling event (e.g., a contract upgrade). Interactions on the brand page or with the customer service unit after the first upselling event are not considered. Furthermore, we capture customer characteristics such as the acquisition channel, consent to receive personalized advertising, and average purchasing power in the customers' ZIP code as well as age and gender. The descriptive statistics of the variables are shown in Table 1.

As previously noted, we first estimate the propensity score with the help of a binary logistic regression in which the dependent variable equals one for customers with social media interactions and zero otherwise. In detail, we match 2077 $(97.7 \%)$ customers with social media interactions prior to their upselling with 2077 customers from the control group. ${ }^{2}$ As shown in Appendix 2, the matching procedure helps significantly reduce the selection bias in the full sample because the treatment and control group are distinct before the matching procedure and exhibit similar characteristics thereafter (based on the percentage reduction in bias; refer to Rosenbaum and Rubin 1985). The average percentage reduction in bias for all variables is $88.3 \%$.

Given the longitudinal character of our data in which the observed customer tenure varies significantly across time and because most of the observations are right censored (because upselling events can occur any time during the customer tenure), we use a survival model to analyze the effect of the social media activity level on the likelihood and timing of the upselling. We choose a parametric Weibull hazard model formulation to account for the baseline trend of the upselling likelihood during the customer lifetime and to allow for a time-varying formulation of our focal variables, pre- and post-purchase interactions, service requests, and service complaints (Grewal et al. 2004; Kamakura et al. 2004). The model defines the hazard rate $h\left(t \mid \boldsymbol{k}_{i}\right)$ for customer $i$ as:

$$
h_{i}\left(t \mid \mathbf{k}_{\mathbf{i}}\right)=h_{0}(t) \exp \left(\mathbf{k}_{\mathbf{i}} \boldsymbol{\beta}_{\mathbf{k}}\right)=\alpha t^{\alpha-1} \exp \left(\beta_{0}+\mathbf{k}_{\mathbf{i}} \boldsymbol{\beta}_{\mathbf{k}}\right)
$$

\footnotetext{
${ }^{2}$ Within a tolerance zone (see Silverman 1986), we are unable to find a perfect matching partner for 82 customers.
} 
with $\mathbf{k}_{\mathbf{i}}=\left(1, k_{i 1}, k_{i 2}, \ldots, k_{i p}\right), \boldsymbol{\beta}_{\mathbf{k}}=\left(\begin{array}{c}\beta_{0} \\ \beta_{1} \\ \vdots \\ \beta_{p}\end{array}\right)$.

In this notation, $\boldsymbol{k}_{i}$ represents the vector of $p$ covariates with the parameter $\beta_{k}$ and the ancillary shape parameter $\alpha$ estimated from the data. The parameter estimates are obtained from maximizing the partial likelihood function (Blossfeld et al. 2007). The dependent variable upselling behavior is defined as a dichotomous variable for which we solely consider the first service upgrade initiated by a customer. The time variable $t$ is defined as the customer lifetime, which is measured in days. Consequently, the dataset used for the estimation includes single observations for every day that passed between a customer's activation and the upselling event, respectively censoring. The focal variables, pre-purchase interactions, postpurchase interactions, service requests, and service complaints, are incorporated as time-varying covariates that account for changes on a daily basis. We excluded service contacts specifically aimed at upgrading a contract (e.g., "I want to book the flat-rate data plan starting September 1.") to prevent endogeneity issues. With variance inflation factors $<1.3$, we observe no collinearity (refer to Appendix 3).

\subsubsection{Results}

The results shown in Table 3 indicate that customers who engage in social media interactions indeed tend to develop their customer relationship further. We find that customer interaction on the brand page increases the propensity for upselling: the coefficient for post-purchase interactions is both significant and positive

Table 3 Influences on upselling behavior

\begin{tabular}{lll}
\hline Variables & Hazard ratio & Sig. \\
\hline Pre-purchase interactions & 0.889 & 0.268 \\
Post-purchase interactions $^{\mathrm{a}}$ & 1.009 & 0.009 \\
Service complaints $_{\text {Service requests }}$ & 1.027 & 0.354 \\
Acquisition channel & 1.020 & 0.923 \\
Purchasing power & 1.026 & 0.704 \\
Advertising consent & 1.026 & 0.380 \\
Credit score & 0.879 & 0.406 \\
Age & 0.735 & 0.000 \\
Gender & 0.990 & 0.103 \\
Intercept & 1.027 & 0.862 \\
Log likelihood & $5.9 \times 10^{-5}$ & 0.000 \\
Chi square & -767.865 & \\
Observations & $30.57 ; p<.001$ & \\
\hline
\end{tabular}

\footnotetext{
a Sum of social media interactions until first upselling event
} 
$(\beta=1.009 ; p<.01)$. While the credit score also affects the timely upsells, we do not find any significant effects of the other covariates on the upselling behavior. Overall, the findings indicate that the higher the activity level is, the earlier the customers upgrade their contract.

\subsection{Social media interactions and customer churn (Study 2)}

\subsubsection{Sample and measurement}

Above, we argued that it is unclear which overall effect social media interactions have on customer retention. Therefore, we analyze the behavior of the 334,111 customers in our sample regarding customer churn. Again, the data include all contractual relationships in which customers commit for 24 months. Because our observation period encompasses more than 27 months and because the contractual termination period ends 3 months before the contract ends, we observe more than one complete contract life cycle for the first cohort of customers (i.e., those who sign up during the first 6 months after launch). In total, we find 105,307 active terminations of contracts, i.e., when customers explicitly cancel the contract according to the regular cancellation policy. Certain churn events occur during the 24-month contract period because some customers terminate their contracts well ahead of time to avoid missing the termination deadline. Customer churn may also result from customers' refusal to pay their fees (Becker et al. 2015). In these cases of passive termination, the customer does not actively cancel the contract; however, the behavior of not fulfilling the financial obligations ultimately results in a termination of the contract by the mobile phone company. ${ }^{3}$

To investigate the relation between social media interactions and customer churn, in the first step, we employ a probit model with sample selection (Van de Ven et al. 1981). For this purpose, we use the full sample of 334,111 customers and apply a Heckman correction to account for the self-selection of Facebook as a communication channel. We employ the same set of explanatory variables as in Study 1, include the upselling behavior and use the sign-up date to account for differences in customer tenure. For the sample selection component, we use the same explanatory variables as in the propensity score matching (i.e., age, gender, usage, and purchasing power). To reduce complexity, we chose all contract terminations as the dependent variable (i.e., both active and passive terminations).

The formal estimation model consists of two components (Greene 2012, p. 790) — an observation rule, $S=1$, and a behavioral outcome (here, churn), $y=0$ or 1:

$$
\begin{array}{ll}
S^{*}=\mathbf{z}_{1}^{\prime} \gamma_{1}+u_{1}, & S=1 \quad \text { if } S^{*}>0, \quad 0 \text { otherwise, } \\
y^{*}=\mathbf{z}_{2}^{\prime} \gamma_{2}+u_{2}, & y=1 \quad \text { if } y^{*}>0, \quad 0 \text { otherwise, }
\end{array}
$$

\footnotetext{
${ }^{3}$ Due to confidentiality reasons, we are not allowed to disclose the exact relation between active and passive terminations.
} 


$$
\begin{gathered}
\left(\begin{array}{l}
u_{1} \\
u_{2}
\end{array} \mid \mathbf{z}_{1}, \mathbf{z}_{2}\right) \sim N\left[\left(\begin{array}{l}
0 \\
0
\end{array}\right),\left(\begin{array}{ll}
1 & \rho \\
\rho & 1
\end{array}\right)\right], \\
\left(y, z_{2}\right) \text { observed only when } S=1 .
\end{gathered}
$$

where $\mathbf{z}_{1}, \mathbf{z}_{2}$ represent the vectors of covariates, $\gamma_{1}, \gamma_{2}$ the corresponding coefficients, and $u_{1}, u_{2}$ the unobservables of the selection and churn equation, respectively.

In the second step of our analysis, we investigate the behavior of active users of the provider's Facebook brand page and non-users over time. Specifically, we analyze social media interactions with respect to their effect on the churn propensity and the resulting customer lifetime. For this purpose, we compute the Kaplan-Meier estimates for active, passive and total contract terminations to measure the customer survival over time for both groups. Analogous to the full sample in Study 2, we use the propensity score matching approach to reduce the selection bias with respect to the social media interactions prior to contract terminations. ${ }^{4}$ The results in "Appendices 1 and 2" indicate that the matched sample has had its biases reduced (on average, $92.9 \%$ for all variables).

\subsubsection{Results}

The results of the probit model with sample selection are presented in Table 4 . We find that the number of social media interactions indeed has a significant and negative effect of $-.008(p<.01)$ on the churn probability. While service complaints with an effect of $.005(p<.05)$ increase the risk of churn, we do not find a significant effect for regular service contacts. As expected, the churn rate increases with the customer tenure, i.e., customers who joined later during the observation period (indicated by the sign-up date) show a lower churn probability of -.0002 $(p<.01)$. The effects of the other covariates are also not surprising for CRM managers: younger, male customers churn more frequently, while previous upselling activities significantly reduce the churn risk.

Furthermore, the Kaplan-Meier estimates depicted in Fig. 1 reveal interesting patterns for the different types of contract terminations. Over the total number of terminations, we find that customers with social media interactions are substantially less likely to terminate their contracts (see Fig. 1a). However, this trend is mainly driven by passive terminations (Fig. 1c) in which the churn probability for social media-active customer is lower than for the control group. For active terminations, the churn probabilities do not differ substantially (Fig. 1b). This finding is interesting because it shows that social media interactions may not necessarily increase loyalty in general (as indicated by the active terminations); however, it at least substantially decreases the likelihood of fraudulent customer behavior, i.e., simply stopping the payment of the contractual fees to trigger a cancellation within the regular contract period. Figure 1c shows that such passive terminations occur

\footnotetext{
${ }^{4}$ In total, we were able to match 4165 of the 4598 customers with social media interactions with the same number from the control group $(90.6 \%)$.
} 
Table 4 Influences on customer churn probability

\begin{tabular}{lll}
\hline Variables & Coef. & Sig. \\
\hline Churn equation (DV = customer churn) & & \\
Social media interactions ${ }^{\mathrm{a}}$ & -0.008 & 0.003 \\
Service complaints & 0.005 & 0.015 \\
Service requests & $-2.7 \times 10^{-4}$ & 0.631 \\
Upselling behavior & -0.167 & 0.000 \\
Acquisition channel & 0.140 & 0.000 \\
Purchasing power & -0.010 & 0.000 \\
Advertising consent & 0.017 & 0.027 \\
Credit score & -0.025 & 0.000 \\
Age & -0.008 & 0.000 \\
Gender & -0.192 & 0.000 \\
Sign-up date & $-2.0 \times 10^{-4}$ & 0.000 \\
Intercept & -1.796 & 0.000 \\
Selection equation (DV use of social media channel) & \\
Usage & $3.4 \times 10^{-4}$ & 0.000 \\
Purchasing power & -0.009 & 0.000 \\
Age & -0.006 & 0.000 \\
Gender & -0.174 & 0.000 \\
Intercept & -1.784 & 0.000 \\
$a$ tanh $\rho^{\mathrm{b}}$ & 4.381 & 0.000 \\
$p$ & 0.999 & \\
Log likelihood & $-26,651$ & \\
Chi square & $721.44 ; p<.001$ & \\
Observations & 334,111 & \\
\hline & &
\end{tabular}

\footnotetext{
${ }^{\text {a }}$ Sum of social media interactions until churn event

b $a \tanh \rho=\frac{1}{z} \ln \left(\frac{1+g}{1-g}\right)$
}

significantly more often for customers without social media interactions than for those with social media interactions.

To test the structural differences in the timing, we analyze the average time to termination for both customer groups (see Table 5). The results for the total number of terminations indicate that customers with social media interactions terminate their contracts significantly later than customers without social media interaction (after 178.01 vs. 126.55 days; $p<0.01$ ). As previously indicated by the KaplanMeier estimates, this pattern solely holds for passive terminations. However, for active terminations, the difference is not significant. Overall, the findings of our analyses indicate that social media interactions correlate positively with longer customer lifetimes. 

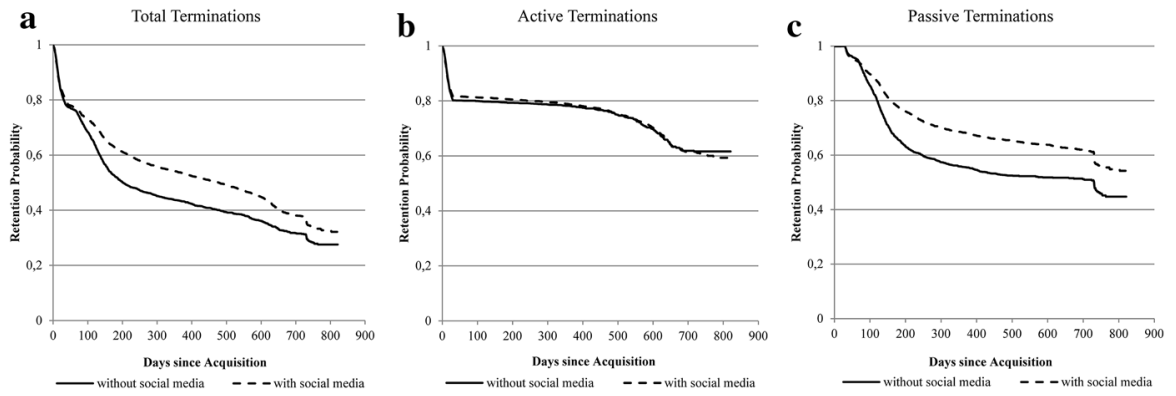

Fig. 1 Kaplan-Meier survival estimates

Table 5 Comparison of average customer lifetime until contract termination

\begin{tabular}{llll}
\hline Termination & $\begin{array}{l}\text { Customers with social } \\
\text { media interactions }\end{array}$ & $\begin{array}{l}\text { Customers without social } \\
\text { media interactions }\end{array}$ & $\begin{array}{l}\text { Significant } \\
\text { difference* }\end{array}$ \\
\hline Active terminations $^{\mathrm{a}}$ & 476.74 & 448.98 & - \\
Passive terminations $^{\mathrm{b}}$ & 125.96 & 101.79 & $\boldsymbol{V}$ \\
Total & 178.01 & 126.55 & $\boldsymbol{V}$ \\
Observations & & & 8330 \\
\hline
\end{tabular}

* Test of differences in mean (two-sided significance on the 0.01 level)

a Values indicate the days until customer canceled the contract

b Values indicate the days until the customer's refusal to pay leads to a cancellation of the contract by the company

\subsection{Social media interactions and service requests (Study 3)}

\subsubsection{Sample and measurement}

Considering that social media provides an alternative channel for customer service, we analyze the effect of social media interactions on the volume of customer service contacts. Research has shown that online communities use customer interactions to reduce call center staff who otherwise would provide customer support (Rosenbaum 2008). Hence, customers who actively engage on brand pages may have fewer contacts with the customer service unit. Again, we performed a propensity score matching for all of the social media interactions prior to the first service contact of our full sample of 334,111 customers during the time of observation (refer to Appendices 1 and 2). We achieved a good bias reduction (average of $91.8 \%$ ) with the matching procedure and identified the service requests and complaints made by customers with and without social media interactions for the matched sample. ${ }^{5}$ To investigate the influence that social media interactions exert on service contacts, we

\footnotetext{
5 Overall, we were able to find a matching partner from the control group for 1458 of the 1512 customers with social media interactions $(96.4 \%)$.
} 
estimate the following seemingly unrelated regression framework (Greene 2012, p. 332):

$$
\mathbf{q}_{\mathbf{i}}=\mathbf{X}_{\mathbf{i}} \delta+\varepsilon_{\mathbf{i}}
$$

with $\mathbf{q}_{\mathbf{i}}=\left(q_{i 1}, q_{i 2}\right)^{\prime}, \boldsymbol{\varepsilon}_{\mathbf{i}}=\left(\varepsilon_{i 1}, \varepsilon_{i 2}\right)^{\prime}$,

$$
\mathbf{X}_{\mathbf{i}}=\left(\begin{array}{cc}
\mathbf{x}_{\mathbf{i} 1} & 0 \\
0 & \mathbf{x}_{\mathbf{i} 2}
\end{array}\right), \quad \boldsymbol{\delta}=\left(\begin{array}{c}
\boldsymbol{\delta}_{1} \\
\boldsymbol{\delta}_{\mathbf{2}}
\end{array}\right),
$$

where we measure the number of contacts $q$ for the two different service instances ( $1=$ requests, $2=$ complaints) for each customer $i$ and $\boldsymbol{X}_{\boldsymbol{j}}$ represents the $8 \times 2$ matrix of explanatory variables (with $\boldsymbol{\delta}$ as the corresponding parameter vector). In detail, we use the focal variable, social media interactions, as well as additional contractual (e.g., advertising consent, upselling behavior, and acquisition channel) and demographic covariates (e.g., age, gender, credit score, and purchasing power). $\varepsilon_{i}$ is a $2 \times 1$ vector of unobservables for which we assume that they are uncorrelated across observations but correlated across equations:

$$
E\left[\boldsymbol{\varepsilon}_{1 a}, \boldsymbol{\varepsilon}_{2 b} \mid \mathbf{X}_{\mathbf{1}}, \mathbf{X}_{\mathbf{2}}\right]=\sigma_{12}, \quad \text { if } a=b \text { and } 0 \text { otherwise. }
$$

\subsubsection{Results}

To analyze whether social media interactions affect service contacts in principle, we compare the average number of service contacts (either request or complaint) for the two groups in the matched sample. The results in Table 6 demonstrate that a difference does exist, which indicates that customers with social media interactions on the firm's Facebook brand page have more service contacts in total (37.9 vs. $29.3 \% ; p<.01)$. Specifically, the results from Table 6 show that the rate of regular service requests is significantly higher for social media users than for customers who have no social media interactions with the firm $(36.7$ vs. $27.3 \% ; p<.01)$. However, for specific service complaints, we do not find significant differences between the groups. Considering the individual nature of customer complaints (e.g., Bearden and Teel 1983), this latter finding appears intuitive. For service failures, both groups need to contact customer service to address their individual complaints.

Table 6 Comparison of service contacts

\begin{tabular}{llll}
\hline $\begin{array}{l}\text { Service } \\
\text { contact }\end{array}$ & $\begin{array}{l}\text { Customers with } \\
\text { social media interactions }\end{array}$ & $\begin{array}{l}\text { Customers without } \\
\text { social media interactions }\end{array}$ & $\begin{array}{l}\text { Significant } \\
\text { difference* }\end{array}$ \\
\hline Service requests & 0.367 & 0.273 & $\boldsymbol{\checkmark}$ \\
Service complaints & 0.012 & 0.020 & - \\
Total & 0.379 & 0.293 & - \\
Observations & & & 2916 \\
\hline
\end{tabular}

Values indicate the average number of service requests or complaints per customer

* Test of differences in mean (two-sided significance on the 0.01 level) 
Table 7 Influences on service contacts

\begin{tabular}{llllll}
\hline Variables & \multicolumn{2}{l}{ Service requests } & & \multicolumn{2}{l}{ Service complaints } \\
\cline { 2 - 3 } & Coef. & Sig. & & Coef. & Sig. \\
\hline Social media interactions $^{\mathrm{a}}$ & 0.058 & 0.100 & & $-3.1 \times 10^{-5}$ & 0.995 \\
Upselling behavior $^{\text {Acquisition channel }}$ & -0.121 & 0.251 & & -0.002 & 0.884 \\
Purchasing power & -0.091 & 0.057 & & 0.002 & 0.704 \\
Advertising consent & 0.001 & 0.881 & & 0.002 & 0.142 \\
Credit score & 0.044 & 0.358 & & 0.006 & 0.380 \\
Age & 0.015 & 0.485 & & 0.005 & 0.062 \\
Gender & -0.003 & 0.133 & & $-3.6 \times 10^{-4}$ & 0.138 \\
Intercept & 0.092 & 0.059 & & -0.001 & 0.874 \\
$R^{2}$ & 0.383 & 0.025 & & -0.014 & 0.539 \\
$F$ value & 0.005 & & & 0.003 & \\
Observations & $2.00 ; p<.05$ & & & $1.07 ; p=0.38$ & \\
\hline
\end{tabular}

${ }^{\text {a }}$ Sum of pre- and post-purchase interactions

After establishing that the effect of social media interactions exists only for service requests, the results of the regression analysis can reveal the intensity of the effect. The results imply that while the effect of social media interaction on service requests is marginally significant, it is not significant for service complaints (see Table 7), thus, confirming the previous finding: because service failures (such as hardware breakdowns, network outage, or invoicing errors) can only be resolved by the provider itself, social care provides little or no potential help. The revealed significant covariate effects are also intuitive: Customers who were acquired online also use the (mostly digital) service channels for service requests more frequently than customers acquired offline. At the same time, demographics that are generally associated with a lower affinity to new technology (e.g., female senior citizens) require more customer service interactions (mostly via telephone).

Overall, we find that interacting with peers in social media communities does not significantly replace service contacts from customers. In contrast to companies' objectives, the results indicate that social media interactions do not adequately substitute for service requests through conventional channels such as telephone and email. To assess whether the increased level of service contacts for social mediaaffluent customers poses a problem for the profitability of managing a brand page, we conduct a profitability analysis as follows.

\section{Profitability of social media interactions}

From a managerial perspective, a key issue is whether the revealed differences between customers with and without social media interactions with the firm translate into economically relevant consequences for their respective profitability. 
Overall, the results from Studies 1-3 imply that customers who engage in social media interaction are more easily retained and are more likely to upgrade their customer relationships but have more service requests. Considering these mixed effects, we would expect social media-active customers to generate both higher revenues and costs. To test the profitability implications of this assumption, we compared the matched sample of 8330 customers with and without social media interactions from Study 2 with respect to the revenues and costs for the focal company. For this purpose, we focus solely on such positions that vary between individual customers. Revenues include the monthly payments based on the selected flat-rate tariff and the upgrade options (such as the data and SMS flat rate). We cannot disclose the direct interconnection cost (i.e., the percentage of revenue that the network operator is charged by the actual network provider) due to confidentiality reasons. Typically, these interconnection costs are fixed per flatrate contract; hence, they are independent of the number of calls, SMS, or data volume and are in the range of $60-90 \%$ of the revenues. Because these interconnection costs are identical between the groups of customers, they do not affect the outcome of our analysis.

The costs are retrieved directly from the firm's internal accounting system and include all variable customer costs, in particular the service costs triggered by contacts via post, email, or phone. For example, we know the exact number of service calls, the exact length of each call, and the attached cost factor for each customer. As a general indication for this industry, call center agents are trained to handle service calls within a 3 min time frame; a typical rate for such a large-scale inbound service operation is approximately 0.50 Euro per minute.

To allow for a valid comparison between customers with and without social media interactions, we report the specific costs of these interactions separately, again using data from internal accounting. The firm employs an in-house team of social media agents who monitor the Facebook page continuously and respond to every post from customers. These fixed costs are attributed to each customer with social media interaction on a per post basis, irrespective of the length or the complexity of the communication. In this industry, the typical rates for such service posts are in the range of a maximum of 1 Euro. ${ }^{6}$

To compare the revenues and costs of both groups with different customer lifetimes, we calculate the average monthly revenues and the average monthly costs per customer. ${ }^{7}$ In accordance with our expectations, the comparison in Table 8 demonstrates that social media-active customers not only generate significantly higher revenues $(+11.1 \%)$ but also cause substantially higher customer service costs $(+135.1 \%)$. However, even if we account for the additional social mediainduced costs, we find that the overall effect on the profitability is positive; the margin with social media interactions is significantly higher $(+5.2 \%$ marginal return) than that without social media interactions. This finding confirms that of

\footnotetext{
${ }^{6}$ Please note that the initial set-up cost of the company's Facebook fan page were negligible and would amount to less than 1 Cent if attributed per customer and month.

7 To comply with a non-disclosure agreement, all reported absolute numbers have been rescaled albeit with an identical factor to maintain the relative magnitudes.
} 
Table 8 Comparison of customer revenues and costs

\begin{tabular}{llll}
\hline Value Component & $\begin{array}{l}\text { Customers with } \\
\text { social media interactions }\end{array}$ & $\begin{array}{l}\text { Customers without } \\
\text { social media interactions }\end{array}$ & $\begin{array}{l}\text { Significant } \\
\text { difference* }\end{array}$ \\
\hline Customer revenues & 21.85 & 19.67 & $\boldsymbol{V}$ \\
Customer costs & 1.34 & 0.57 & $\checkmark$ \\
Service costs & 0.42 & - & $\checkmark$ \\
Social media costs & 20.09 & 19.10 & 8330 \\
Total & & & $\checkmark$ \\
Observations & & & \\
\hline
\end{tabular}

Values indicate the revenues and costs in Euro; customer costs involve mainly customer service and operational costs, they do not include the interconnection costs paid to the network provider which are structured as a fixed percentage of the revenues

* Test of differences in mean (two-sided significance on the 0.01 level)

Libai et al. (2010), who suggested that customer interactions in social communities can build customer equity.

Of course, this positive return is dependent on an efficient handling of social media interactions, which is easier to achieve for large-scale operations that handle hundreds of thousands or millions of customers. To test the robustness of our finding, we conducted a scenario analysis that assumes a wide range of cost per post. We find that in our empirical application, the break-even for the fostering social media interactions' approach costs approximately 5 Euro per post, which is several multiples of the actual cost per post that was observed, although the firm employed a conservative cost attribution. For firms that can leverage larger scale effects (e.g., telecommunication providers often have millions or tens of millions of customers) or utilize outsourcing to low-cost countries overseas (which is not possible, for example, for a provider in the German language area), the potential returns of a social media interaction strategy may be considerably higher.

\section{Conclusion}

This study provides a wide range of empirical insights that indicate that the interaction of customers with a firm through social media channels eases the upselling efforts and reduces the risk of churn but increases the number of service requests for this group of customers. Considering all of the analyses, corrected for selection biases and possible endogeneity issues, the results demonstrate that the significant differences in customers' upselling behavior, churn, service contacts and, ultimately, profitability are actually caused by the specific interactions of customers through the brand page. For example, the higher propensity to upgrade the contract could be due to higher loyalty, which is fostered by active participation in the brand community. In addition, the results imply that although the brand page interaction may not help preemptively resolve questions or concerns, they do indeed increase 
customers' tendency to engage in "real" dialogue with the company. This finding is supported by the significantly higher number of events in the traditional service and support channels, such as the call center or email. Experiencing the company's response to customer queries in social media certainly lowers the customer's inhibition threshold to contact the company via other channels.

Given the exploratory nature of these studies and the novelty of this research domain, we face several limitations that must be considered. First, the setting in the telecommunication industry has certain particular characteristics, such as the common 24-month contracts, which are not applicable to other fields. Although the observation period of more than 850 days is definitely not short by general standards, observations throughout multiple contract periods would provide potentially valuable further insights into customer retention.

Second, although we have access to an extensive range of customer data, certain limitations remain. Due to legal restrictions, we are not able to identify or track the social media activities of customers outside the brand page. Additionally, the analysis of the actual contents of the interactions is limited. Thus far, a very basic evaluation of the overall valence of initial posts in a specific thread is available (ca. $46 \%$ of these first posts have negative tonality, and ca. $54 \%$ have positive to neutral tonality). Though the found effects hold despite this large share of negative comments, future research may more closely examine the role of sentiment (Schweidel and Moe 2014). Such additional data would also help to account for heterogeneity, particularly in those exploratory studies that are currently based on simple mean comparisons. While we capture observable heterogeneity by including key control variables (such as gender, age, or acquisition channel) in our multivariate models, future research should try to consider unobserved heterogeneity as well. This applies in particular to future developments of the rather hands-on approach of our profitability analysis.

Finally, research into the causal mechanisms of social interactions that lead to higher profitability requires additional approaches, such as laboratory or field experiments or other, more behavioral techniques. Such approaches would especially help determine whether social media interactions are rather reflections of underlying attitudes or actually forming the attitudes regarding the product or service in question.

However, this study's results already indicate that social media interactions may influence customer management variables and, ultimately, profitability. Given the initial insights of this study and, in particular, the significant difference in the profitability between the groups with and without social media interaction, this topic is highly relevant for marketing managers and will surely provide substantial opportunities for further research.

Acknowledgments The authors thank Karen Gedenk and Mark Heitmann for their helpful comments on previous versions of this article. All authors have contributed equally and should be considered co-first authors.

Open Access This article is distributed under the terms of the Creative Commons Attribution 4.0 International License (http://creativecommons.org/licenses/by/4.0/), which permits unrestricted use, 
distribution, and reproduction in any medium, provided you give appropriate credit to the original author(s) and the source, provide a link to the Creative Commons license, and indicate if changes were made.

\section{Appendix 1}

\section{See Table 9.}

Table 9 Determinants of social media interaction propensity

\begin{tabular}{|c|c|c|c|c|c|c|}
\hline \multirow[t]{3}{*}{ Variables } & \multicolumn{6}{|c|}{ Matched sample } \\
\hline & \multicolumn{2}{|c|}{ Upselling } & \multicolumn{2}{|c|}{ Terminations } & \multicolumn{2}{|c|}{ Service requests } \\
\hline & Coef. & Sig. & Coef. & Sig. & Coef. & Sig. \\
\hline Usage & 0.001 & 0.000 & 0.000 & 0.001 & 0.000 & 0.000 \\
\hline Purchasing power & -0.028 & 0.001 & -0.019 & 0.001 & -0.021 & 0.041 \\
\hline Age & -0.019 & 0.000 & -0.016 & 0.000 & -0.018 & 0.000 \\
\hline Gender & -0.559 & 0.000 & -0.446 & 0.000 & -0.559 & 0.000 \\
\hline Intercept & -3.710 & 0.000 & -3.149 & 0.000 & -4.157 & 0.000 \\
\hline
\end{tabular}

Dependent variable $1=$ social media interactions. $N=334,111$

\section{Appendix 2}

See Table 10.

Table 10 Percentage reduction in bias

\begin{tabular}{llll}
\hline Variables & \multicolumn{2}{l}{ Matched sample } & \\
\cline { 2 - 4 } & Upselling & Terminations & Service requests \\
\hline Usage & 0.84 & 0.96 & 0.95 \\
Purchasing power & 0.81 & 0.83 & 0.82 \\
Age & 0.89 & 0.93 & 0.95 \\
Gender & 0.99 & 0.99 & 0.95 \\
Average & 0.88 & 0.93 & 0.92 \\
Observations & 4154 & 8330 & 2916 \\
\hline
\end{tabular}

The differences in observations are a result of the different number of customers with social media interactions up until the first service request, the first upselling event, and the contract termination, respectively. The percentage reduction bias was calculated following Rosenbaum and Rubin (1985); $N=334,111$ 


\section{Appendix 3}

See Table 11.

Table 11 Correlations for matched sample upselling

\begin{tabular}{llllllll}
\hline & VIF & \multicolumn{1}{l}{ 1. } & \multicolumn{1}{l}{ 2. } & \multicolumn{1}{l}{3.} & \multicolumn{1}{l}{4.} & 5. & 6. \\
\hline 1. Pre-purchase interactions & 1.03 & 1.000 & & & & & \\
2. Post-purchase interactions & 1.05 & $\mathbf{0 . 1 4 7}$ & 1.000 & & & & \\
3. Service complaints & 1.24 & 0.003 & $\mathbf{0 . 1 2 2}$ & 1.000 & & & \\
4. Service requests & 1.25 & 0.010 & $\mathbf{0 . 1 3 2}$ & $\mathbf{0 . 4 3 5}$ & 1.000 & & \\
5. Purchasing power & 1.01 & -0.032 & -0.001 & -0.013 & -0.010 & 1.000 & \\
6. Credit score & 1.02 & -0.024 & 0.009 & -0.001 & $-\mathbf{0 . 0 4 7}$ & $\mathbf{0 . 0 5 2}$ & 1.000 \\
7. Age & 1.01 & $\mathbf{0 . 0 4 3}$ & -0.008 & -0.009 & -0.016 & -0.039 & 0.092 \\
\hline
\end{tabular}

Significant correlations are marked bold (two-sided significance on the 0.01-level), $N=4154$

\section{References}

Aksin, Zeynep, Mor Armony, and Vijay Mehrotra. 2007. The modern call center: a multi-disciplinary perspective on operations management research. Production and Operations Management 16(6): 665-688.

Armelini, Guillermo, Christian Barrot, and Jan U. Becker. 2015. Referral programs, customer value, and the relevance of dyadic characteristics. International Journal of Research in Marketing 32(4): 449-452.

Bearden, William O., and Jesse E. Teel. 1983. Selected determinants of consumer satisfaction and complaint reports. Journal of Marketing Research 20(1): 21-28.

Becker, Jan U., Martin Spann, and Timo Schulze. 2015. Implications of minimum contract durations on customer retention. Marketing Letters 26(4): 579-592.

Bernoff, Josh, and Ted Schadler. 2010. Empowered. Harvard Business Review 88(7/8): 94-101.

Blossfeld, Hans-Peter, Götz Rohwer, and Katrin Golsch. 2007. Event history analysis with stata. Mahwah: Lawrence Erlbaum.

Bolton, Ruth, and Shruti Saxena-Iyer. 2009. Interactive services: a framework, synthesis and research directions. Journal of Interactive Marketing 23(1): 91-104.

Brodie, Roderick J., Ana Ilic, Biljana Juric, and Linda Hollebeek. 2013. Consumer engagement in a virtual brand community: an exploratory analysis. Journal of Business Research 66(1): 105-114.

Caliendo, Marco, Michel Clement, Dominik Papies, and Sabine Scheel-Kopeinig. 2012. The costs of spam and the impact of spam filters. Information Systems Research 23(3): 1068-1080.

Chevalier, Judith, and Dina Mayzlin. 2006. The effect of word of mouth on sales: online book reviews. Journal of Marketing Research 43(August): 345-354.

De Vries, Lisette, Sonja Gensler, and Peter S.H. Leeflang. 2012. Popularity of brand posts on brand fan pages: an investigation of the effects of social media marketing. Journal of Interactive Marketing 26(2): 83-91.

Dichter, Ernest. 1966. How word-of-mouth advertising works. Harvard Business Review 44(6): 147-166.

Digitalbuzz. 2011. Infographic: the real cost of social media. http://www.digitalbuzzblog.com/infographic-cost-of-social-media/?goback=.gde_2255455_member_66415405. Accessed 15 Dec 2015.

Donnelly Jr, James H., and John M. Ivancevich. 1970. Post-purchase reinforcement and back-out behavior. Journal of Marketing Research 7(3): 399-400.

Downing, James W., Charles M. Judd, and Markus Brauer. 1992. Effects of repeated expressions on attitude extremity. Journal of Personality and Social Psychology 63(1): 17-29. 
Elsner, Mark K., Oliver P. Heil, and Atanu R. Sinha. 2010. How social networks influence the popularity of user-generated content. Marketing Science Institute. Special Report 10-206.

Garnefeld, Ina, Andreas Eggert, Sabrina V. Helm, and Stephen S. Tax. 2013. Growing existing customers' revenue streams through customer referral programs. Journal of Marketing 77(July): 17-32.

Gensler, Sonja, Franziska Völckner, Liu-Thompkins Yuping, and Caroline Wiertz. 2013. Managing brands in the social media environment. Journal of Interactive Marketing 27(4): 242-256.

Greene, William H. 2012. Econometric analysis, 7th ed. Harlow: Pearson.

Grewal, Rajdeep, Raj Mehta, and Frank R. Kardes. 2004. The timing of repeat purchases of consumer durable goods: the role of functional bases of consumer attitudes. Journal of Marketing Research 41(1): 101-115.

Gruner, Richard, Christian Homburg, and Bryan Lukas. 2014. Firm-hosted online brand communities and new product success. Journal of the Academy of Marketing Science 42(1): 29-48.

Heckman, James J. 1979. Sample selection bias as a specification error. Econometrica 47(1): 153-161.

Hennig-Thurau, Thorsten, Kevin P. Gwinner, Gianfranco Walsh, and Dwayne D. Gremler. 2004. Electronic word-of-mouth via consumer-opinion platforms: what motivates consumers to articulate themselves on the Internet? Journal of Interactive Marketing 18(1): 38-52.

Hennig-Thurau, Thorsten, Charles F. Hofacker, and Björn Bloching. 2013. Marketing the pinball way: understanding how social media change the generation of value for consumers and companies. Journal of Interactive Marketing 27(4): 237-241.

Hennig-Thurau, Thorsten, Edward C. Malthouse, Christian Friege, Sonja Gensler, Lara Lobschat, Arvind Rangaswamy, and Bernd Skiera. 2010. The impact of new media on customer relationships. Journal of Service Research 13(3): 311-330.

Hennig-Thurau, Thorsten, Caroline Wiertz, and Fabian Feldhaus. 2015. Does Twitter matter? The impact of microblogging word of mouth on consumers' adoption of new movies. Journal of the Academy of Marketing Science 43(3): 375-394.

Hinz, Oliver, Bernd Skiera, Christian Barrot, and Jan U. Becker. 2011. Seeding strategies for viral marketing: an empirical comparison. Journal of Marketing 75(4): 55-71.

Hoffman, Donna L., and Marek Fodor. 2010. Can you measure the ROI of your social media marketing. MIT Sloan Management Review 52(1): 41-49.

Kamakura, Wagner A., Bruce S. Kossar, and Michel Wedel. 2004. Identifying innovators for the crossselling of new products. Management Science 50(8): 1120-1133.

Kaplan, Andreas M., and Michael Haenlein. 2010. Users of the world, unite! The challenges and opportunities of social media. Business Horizons 53(1): 59-68.

Kumar, V., Lerzan Aksoy, Bas Donkers, Rajkumar Venkatesan, Thorsten Wiesel, and Sebastian Tillmanns. 2010. Undervalued or overvalued customers: capturing total customer engagement value. Journal of Service Research 13(3): 297-310.

Labrecque, Lauren I. 2014. Fostering consumer-brand relationships in social media environments: the role of parasocial interaction. Journal of Interactive Marketing 28(2): 134-148.

Libai, Barak, Ruth Bolton, Marnix S. Bügel, Ko de Ruyter, Oliver Götz, Hans Risselada, and Andrew T. Stephen. 2010. Customer-to-customer Interactions: broadening the scope of word of mouth research. Journal of Service Research 13(3): 267-282.

Malthouse, Edward C., Michael Haenlein, Bernd Skiera, Egbert Wege, and Michael Zhang. 2013. Managing customer relationships in the social media era: introducing the social CRM house. Journal of Interactive Marketing 27(4): 270-280.

McAlexander, James H., John W. Schouten, and Harold F. Koenig. 2002. building brand community. Journal of Marketing 66(1): 38-54.

Morwitz, Vicki G., Eric Johnson, and David Schmittlein. 1993. Does measuring intent change behavior? Journal of Consumer Research 20(1): 46-61.

Mudambi, Susan M., and David Schuff. 2010. What makes a helpful online review? a study of customer reviews on Amazon.com. MIS Quarterly 34(1): 185-200.

Muniz, Albert M., and Thomas C. O'Guinn. 2001. Brand community. Journal of Consumer Research 27(March): 412-432.

Neslin, Scott A., Sunil Gupta, Wagner Kamakura, Lu Junxiang, and Charlotte H. Mason. 2006. Defection detection: measuring and understanding the predictive accuracy of customer churn models. Journal of Marketing Research 43(2): 204-211.

Neslin, Scott A., and Venkatesh Shankar. 2009. Key issues in multichannel customer management: current knowledge and future directions. Journal of Interactive Marketing 23(1): 70-81. 
Peters, Kay, Yubo Chen, Andreas M. Kaplan, Björn Ognibeni, and Koen Pauwels. 2013. Social media metrics - a framework and guidelines for managing social media. Journal of Interactive Marketing 27(4): 281-298.

Rosenbaum, Mark S. 2008. Return on community for consumers and service establishments. Journal of Service Research 11(2): 179-196.

Rosenbaum, Paul R., and Donald B. Rubin. 1983. The central role of the propensity score in observational studies for causal effects. Biometrika 70(1): 41-55.

Rosenbaum, Paul R., and Donald B. Rubin. 1985. Constructing a control group using multivariate matched sampling methods that incorporate the propensity score. American Statistician 39(1): 33-38.

Rubin, Donald B., and Neal Thomas. 2000. Combining propensity score matching with additional adjustments for prognostic covariates. Journal of the American Statistical Association 95(450): 573-585.

Schau, Hope Jensen, Albert M. Muñiz, and Eric J. Arnould. 2009. How brand community practices create value. Journal of Marketing 73(5): 30-51.

Schweidel, David A., and Wendy W. Moe. 2014. Listening in on social media: a joint model of sentiment and venue format choice. Journal of Marketing Research 51(August): 387-402.

Silverman, Bernard W. 1986. Density estimation: for statistics and data analysis. London: Chapman and Hall.

The Nielsen Company. 2012. State of the media: The social media report. New York.

de Ven, Van, P.M.M. Wynand, and Bernard M.S. Van Praag. 1981. The demand for deductibles in private health insurance: a probit model with sample selection. Journal of econometrics 17(2): 229-252.

Doorn, Van, Katherine N. Jenny, Vikas Mittal Lemon, Stephan Nass, Doreén Pick, Peter Pirner, and Peter C. Verhoef. 2010. Customer engagement behavior: theoretical foundations and research directions. Journal of Service Research 13(3): 253-266.

Van Laer, Tom, and Ko De Ruyter. 2010. In stories we trust: How narrative apologies provide cover for competitive vulnerability after integrity-violating blog posts. International Journal of Research in Marketing 27(2): 164-174.

Van Noort, Guda, and Lotte M. Willemsen. 2012. Online damage control: the effects of proactive versus reactive webcare interventions in consumer-generated and brand-generated platforms. Journal of Interactive Marketing 26(3): 131-140.

Verhoef, Peter C., Werner J. Reinartz, and Manfred Krafft. 2010. Customer engagement as a new perspective in customer management. Journal of Service Research 13(3): 247-252.

Ward, James C., and Amy L. Ostrom. 2006. Complaining to the masses: the role of protest framing in customer-created complaint web sites. Journal of Consumer Research 33(2): 220-230.

Weinberg, Bruce D., and Ekin Pehlivan. 2011. Social spending: managing the social media mix. Business Horizons 54(3): 275-282.

Yadav, Manjit S., Kristine de Valck, Thorsten Hennig-Thurau, Donna L. Hoffman, and Martin Spann. 2013. Social commerce: a contingency framework for assessing marketing potential. Journal of Interactive Marketing 27(4): 311-323. 